\title{
Dynamic Response of Cable-Supported Façades Subjected to High-Level Air Blast Loads: Numerical Simulations and Mitigation Techniques
}

\author{
Claudio Amadio and Chiara Bedon \\ Department of Civil Engineering and Architecture, University of Trieste, Piazzale Europa 1, 34127 Trieste, Italy \\ Correspondence should be addressed to Chiara Bedon, bedon@dicar.units.it
}

Received 16 April 2012; Revised 18 August 2012; Accepted 5 September 2012

Academic Editor: Laurent Mevel

Copyright (C) 2012 C. Amadio and C. Bedon. This is an open access article distributed under the Creative Commons Attribution License, which permits unrestricted use, distribution, and reproduction in any medium, provided the original work is properly cited.

A glazing façade subjected to blast loads has a structural behaviour that strongly differs from the typical response of a glazing system subjected to ordinary loads. Consequently, sophisticated modelling techniques are required to identify correctly its criticalities. The paper investigates the behaviour of a cable-supported façade subjected to high-level blast loading. Nonlinear dynamic analyses are performed in ABAQUS/Explicit using a sophisticated FE-model (M01), calibrated to dynamic experimental and numerical results. The structural effects of the total design blast impulse, as well as only its positive phase, are analyzed. At the same time, the possible cracking of glass panels is taken into account, since this phenomenon could modify the response of the entire façade. Finally, deep investigations are dedicated to the bearing cables, since subjecting them to elevated axial forces and their collapse could compromise the integrity of the cladding wall. Based on results of previous studies, frictional devices differently applied at their ends are presented to improve the response of the façade under the impact of a high-level explosion. Structural effects of various solutions are highlighted through dynamic simulations. Single vertical devices, if appropriately calibrated, allow reducing significantly the axial forces in cables, and lightly the tensile stresses in glass panes.

\section{Introduction}

Modern buildings are frequently clad with futuristic glazing façades. In them, glass panels have not only architectural and aesthetic functions, but constitute structural components able to interact with the supporting metallic systems (frames, connectors, pretensioned cables).

Recently, numerous authors studied the dynamic response of different glass-cladding typologies, giving particular attention to the effects of initial imperfections [1], wind loads [2], or seismic events [3]. In the last years, also the blast-resistance of glass curtain walls received a remarkable increase of interest. Norville and Conrath [4] proposed simplified procedures for the design of blast resistant glazing elements. Larcher et al. [5] numerically simulated the behaviour of laminated glass loaded by air blast waves, by taking into account also the cracking of glass panes. Weggel and Zapata [6] numerically investigated the dynamic behaviour of a nearly conventional laminated glass curtain wall with split screw spline mullions subjected to lowlevel blast loading. Generally, the principal objective in the design of blast-resistant glazing systems consists in avoiding injuries and minimizing the structural damages. To guarantee these important objectives, the fixing components and the cladding wall should be able to resist the incoming blast wave. At the same time, they should be able to dissipate as much energy as possible, to minimize damages.

In this context, the use of appropriate devices, could improve the dynamic response of the glazing system affected by air blast loading. In $[7,8]$, the authors proposed two specific typologies of dissipative devices able to mitigate the effects of high-level explosions in the main components of cable-supported façades. The first [7] consists in elastoplastic devices introduced at the top of the bearing cables and able to manifest their main structural advantages in the cables. The second [8] consists in viscoelastic spider connectors 
introduced in the points of connection between the glass panels and the pretensioned cables. As a result, the glass panels and the cables are strongly mitigated. Also Wellershoff [9] recently proposed, for blast enhanced cable-supported façades, the use of glass clamp-cable connectors and cableend-connectors able to work as crash absorbers and to plasticize when the explosion occurs.

As shown in $[7,8]$, the simulation of the dynamic response of a cable-supported façade subjected to high-level blast loads requires sophisticated modelling techniques. At the same time, numerical results depend on several factors that are very complex to be described accurately and with certainty (blast pulse, glass cracking, etc.). In this context, some modelling simplifications could be useful for designers in the analysis of similar glazing systems. Based on numerical results proposed in $[7,8]$, the paper numerically investigates the behaviour of the same cable-supported façade subjected to a high-level blast loads. Nonlinear analyses performed using a detailed FE-model (M01) are presented to highlight the criticalities of the conventional glazing system. In M01 FE-model, to ensure the accuracy of simulations, the structural components of a single modular unit are precisely described (laminated glass panels, pretensioned cables, 2hole and 4-hole spider connectors). A brittle cracking model based on fracture mechanics is used to take into account the possible breakage of glass panels due to the design blast load. The examined high-level explosion seriously affects the glass panes and the bearing cables, since an abrupt and significant increase of tensile stresses occurs in them. Nevertheless, as discussed in the paper, the cracking of glass sheets interests only a restricted area of the glazing surface. Consequently, as shown by performing incremental analyses on a linear elastic FE-model (M02), glass breakage has negligible effects on the global dynamic response of the studied façade. In addition, performed simulations allowed to notice that the only positive phase of the design blast load involves in the façade components higher stresses than the total impulse. However, elevated axial forces occur in the bearing cables, and their abrupt rupture could cause the collapse of the entire façade. Because of this reason, appropriate frictional devices, installed at the top or at both the ends of the cables, are proposed to improve the global dynamic response of the façade. Differing from investigations proposed in [7], several technological solutions are numerically investigated (single vertical device, double vertical devices, double horizontal devices) by performing incremental nonlinear analyses on the linear elastic M02 FE-model equipped by devices. Finally, results of parametric simulations are discussed to individuate the optimal solution, both in structural and energy terms.

\section{Blast Resisting Cable-Supported Façades}

The studied cable-supported façade is $L=9.00 \mathrm{~m}$ tall and consists in nominal $1.55 \mathrm{~m} \times 3.00 \mathrm{~m}$ laminated glass sheets (Figure $1[7,8]$ ). To simplify the analysis, the façade is assumed to be wide enough to neglect its lateral restraints $(B \gg L)$. Each laminated panel has a total thickness $t=24.5 \mathrm{~mm}$, obtained by assembling two external fully tempered glass panes $\left(t_{1}=t_{2}=10 \mathrm{~mm}\right)$ and a middle PVBinterlayer $\left(t_{\mathrm{PVB}}=4.5 \mathrm{~mm}\right)$. Vertical $\phi=36 \mathrm{~mm}$ diameter harmonic steel cables (axial stiffness $k_{\text {cable }} \cong 11300 \mathrm{kN} / \mathrm{m}$ ) are subjected to an initial pretension $H_{0}=300 \mathrm{kN}$. Each glass sheet is six-point supported and joined at the cables whit stainless steel spider connectors.

\section{Air Blast Wave}

An explosive blast wave is characterized by an instantaneous rise, a rapid decay and a relatively short duration. A positive and a negative phase describe the pressure-time history (shock wave) associated to a generic ground explosion. In the specific example, a high-level air blast load (Level D-GSA [10]) was taken into account to study the behavioural trends of the investigated façade. For this purpose, a numerical code developed at University of Trieste was used. The code defines the positive phase by means of the exponential equation proposed by Friedlander and discussed in [11]:

$$
p(t)=p_{0}\left(1-\frac{t}{t_{d}^{+}}\right) e^{-k_{p}\left(t / t_{d}^{+}\right)}, \quad 0 \leq t \leq t_{d}^{+} .
$$

Equation (1) fits the pressure waveform $p(t)$ in the interval comprised between the instant $t=0$ of maximum overpressure $p_{0}$ and the instant $t=t_{d}^{+}$at the end of the positive phase.

As proposed in (1), the overpressure $p(t)$ is evaluated by the numerical code as a function of three factors: the distance between the explosion source and the invested building (stand-off distance), the height of the explosion source from ground and the quantity of explosive (equivalent mass of TNT). The static overpressure peak $p_{0}$ is defined in accordance with the suggestions of the TM 5-1300 code [12]. In addition, the shape coefficient $k_{p}$, representative of the velocity of decay of the overpressure peak $p_{0}$ is automatically calculated by the numerical code. Finally, the negative phase of the pressure-time history has an approximate triangular shape, as proposed in [12].

The main outputs of the code are the impulse per unit of surface $(i=613.7 \mathrm{kPams})$, the static overpressure peak $\left(p_{0}=69.9 \mathrm{kPa}\right)$, the duration of the positive phase $\left(t_{d}^{+}=0.02 \mathrm{~s}\right)$, and the corresponding time-varying pressure function (Figure 2).

\section{FE Model of the Façade (M01)}

A single $1.55 \mathrm{~m} \times 9.00 \mathrm{~m}$ modular unit was taken into account for the studied curtain wall and the effects on its components of a high-level blast loading were analyzed (Figure 1). The cable-supported glazing façade was modelled using the general-purpose, finite element computer program ABAQUS/Explicit [13]. An accurate cable-glass FE-model (M01) was firstly developed, in which the main components of a single façade-module have been precisely described (three laminated glass panels, a series of half-spider connectors, a pair of cables, $[7,8])$. This FE-model was used to preliminary investigate the nonlinear behavioural trends of the studied glazing system. Particular attention was dedicated to the modelling of spider connectors, as 


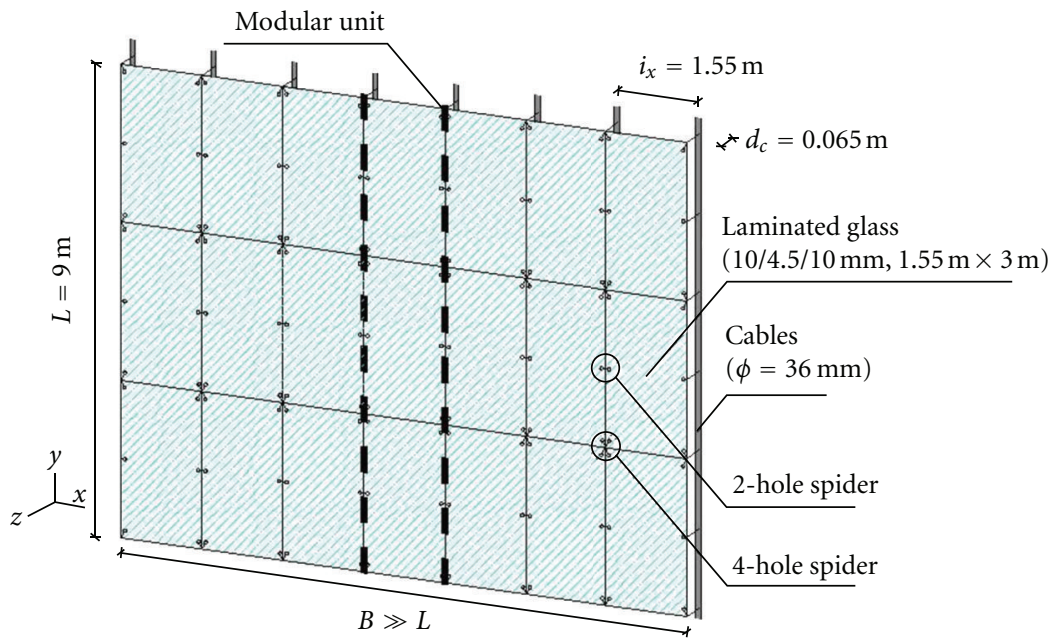

Figure 1: Schematic rendering of the studied cable-supported façade.

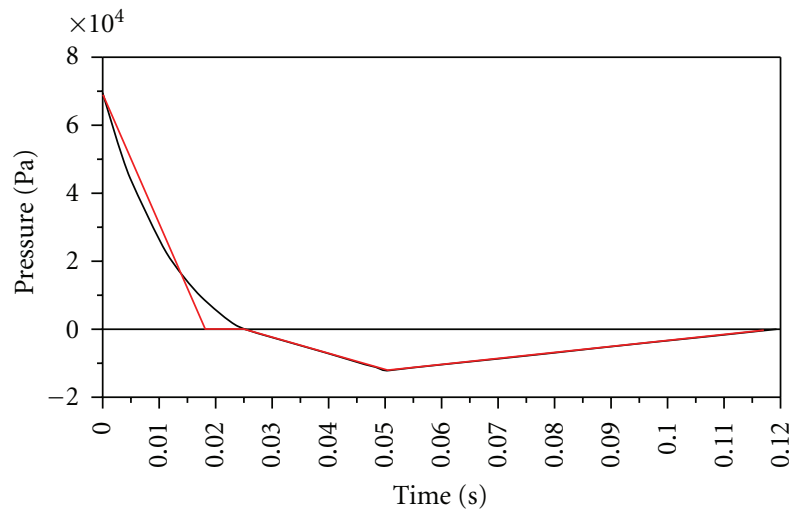

Level D-GSA

— Friedlander

— TM5-1300

Figure 2: Pressure-time history for a Level D-GSA air blast loading [10].

well as to the description of the possible cracking of glass panes. Undoubtedly, glass is a brittle material and its possible cracking due to air blast loading should not be ignored in performing numerical analyses. However, as discussed in the following sections, glass cracking has negligible effects on the behavioural trends of the examined glazing system. As a result, a linear elastic FE-model (M02) could be able to provide realistic results.

At the same time, the effects of the total impulse or the only positive phase of the design blast load were compared. As shown, the only positive phase involves higher tensile stresses in the façade components, thus it could constitute a more prudential and conservative design condition for the analysis of similar cable-supported glazing systems.

4.1. Geometry Description. Laminated glass panels were described by using four-node, quadrilateral stress/displacement composite shell elements with reduced integration

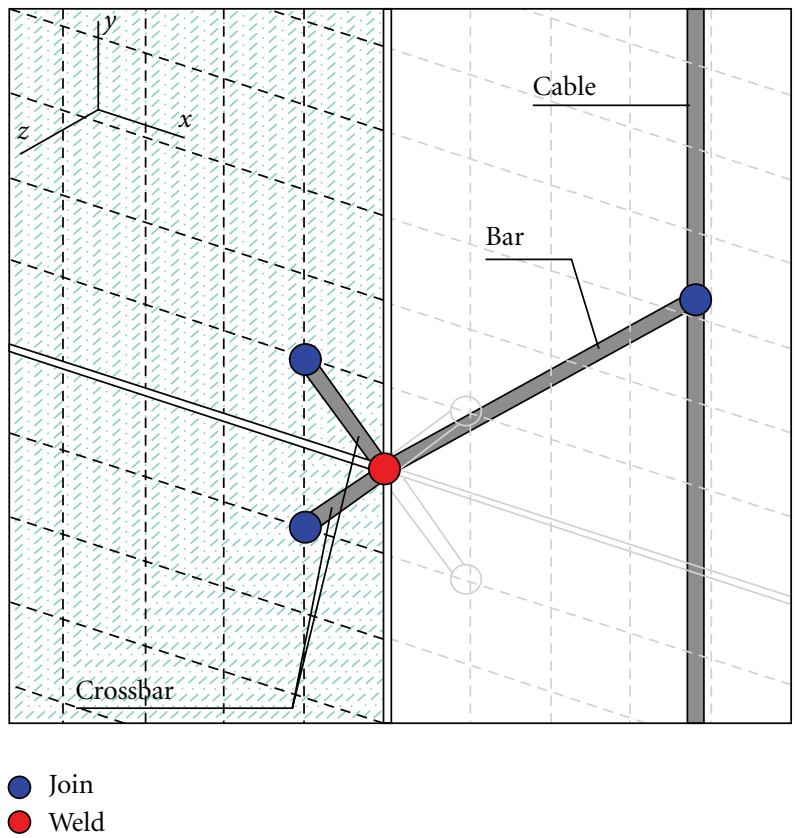

FIgURE 3: Detail of half-spider connector (4-hole, ABAQUS).

and large-strain formulation (S4R). Meshing of the model was based on $200 \mathrm{~mm}$ square module. The transversal ( $x$ direction) displacements of laminated glass panels were constrained, so that when subjected to blast wave pressures the façade-module could only oscillate in $z$-direction. Similarly, $R_{z}$ rotations along the vertical edges of each laminated panel were constrained (Figure 3 ).

Each $\phi=36 \mathrm{~mm}$ diameter cable consisted in 2-node linear displacement truss elements (T3D2), having a crosssection area equal to half the nominal one. In this preliminary phase, the cables were pinned at the upper end and the initial pretension force $\left(H_{0}=300 \mathrm{kN}\right)$ was imposed at their base in the form of a vertical displacement. Along the 
TABLE 1: Material properties (M01 FE-model).

\begin{tabular}{|c|c|c|c|c|}
\hline & Young's modulus $\left[\mathrm{N} / \mathrm{m}^{2}\right]$ & Poisson's ratio $[-]$ & Density $\left[\mathrm{kg} / \mathrm{m}^{3}\right]$ & Behaviour $[-]$ \\
\hline Glass panes & $7 \times 10^{10}$ & 0.23 & 2490 & Brittle-elastic \\
\hline PVB-film & $5 \times 10^{8}$ & 0.50 & 1100 & Elastoplastic \\
\hline Harmonic steel (cables) & $1.3 \times 10^{11}$ & 0.32 & 7300 & Linear elastic \\
\hline Stainless steel (spider devices) & $2.1 \times 10^{11}$ & 0.32 & 7300 & Linear elastic \\
\hline
\end{tabular}

elevation of the façade-module, only $U_{z}$ displacements and $R_{x}$ rotations were allowed for the cables nodes. Structural silicone sealant bonding glass panes was neglected, since it provides a negligible rotational stiffness $[7,8]$. Finally, each half-spider connector consisted in three rigidly connected 2-node linear beams (B31, Figure 3). A weld connector $\left(u_{x}, u_{y}, u_{z}=0, r_{x}, r_{y}, r_{z}=0\right)$ was introduced to link the half-spider components. Additional joins $\left(u_{x}, u_{y}, u_{z}=0\right)$ were introduced in the linked glass-spider and spider-cable nodes.

Due to the impulsive nature of explosions, structural and aerolastic damping effects, as well as additional dissipative contributions implicitly provided by other components of the façade-module (spider connectors, silicone sealant, etc.), were ignored.

4.2. Material Properties. To highlight the effects of glass cracking on the structural response of the entire façade, a model based on fracture mechanics was used for M01 FEmodel [13]. In ABAQUS/Explicit, the brittle cracking option allows to describe the cracking initiation in the behaviour of materials similar to glass, which are dominated by tensile cracking. In this smeared model, a simple Rankine criterion is taken into account: once the preestablished tensile failure stress $\sigma_{R}$ is reached, the glass pane cracks. Cracking is irrecoverable, that is if a crack occurs in glass, it remains throughout the entire analysis. However, permanent strains associated with cracking are neglected and cracks can close completely if stresses across them become compressive, and reopen. In the specific circumstance, in accordance with Weggel and Zapata [6], no dynamic increase was applied to glass strength to account for very high loading rate, thus the tensile strength of fully tempered glass was assumed equal to $\sigma_{R}=120 \mathrm{MPa}$. To perform simulations, the brittle cracking option of ABAQUS/Explicit requires the specification of several fracture and postfailure parameters able to describe the behaviour of glass sheets after cracking. Undoubtedly, these cracking and postcracking factors should be calibrated with attention, since they represent an important aspect in simulations. For this purpose, preliminary parametric investigations and comparisons with experimental results available in literature were performed to validate the used parameters. In this paper, specifically, a value $G_{f}^{I}=100 \mathrm{~J} / \mathrm{m}^{2}$ was taken into account for the fracture energy of glass [1315]. At the same time, the postcracked behaviour of glass was described through the ABAQUS/Explicit brittle shear option, in which the postcracked shear stiffness of glass is defined as a function of the opening strain across the crack. Shear retention can be expressed in the power law form as:

$$
\rho\left(e_{\mathrm{nn}}^{\mathrm{ck}}\right)=\left(1-\frac{e_{\mathrm{nn}}^{\mathrm{ck}}}{e_{\mathrm{max}}^{\mathrm{ck}}}\right)^{p},
$$

where $\rho\left(e_{\mathrm{nn}}^{\mathrm{ck}}\right)$ is the shear retention factor, $e_{\mathrm{nn}}^{\mathrm{ck}}$ is the crack opening strain, $p$ and $e_{\max }^{\mathrm{ck}}$ are material parameters. In this circumstance, the values $p=1$ and $e_{\max }^{\mathrm{ck}}=0.1$ were assumed. Furthermore, to simulate the behaviour of PVB-interlayer, an elastoplastic characteristic curve $\left(\sigma_{y}, \mathrm{PVB}=11 \mathrm{MPa}\right)$ and a failure strain of $300 \%$ were taken into account [5]. Since explosions are characterized by very short duration and the behaviour of PVB-films strongly depends on loading time, a glassy shear modulus $G_{\mathrm{PVB}}$ was considered, with $E_{\mathrm{PVB}}=500 \mathrm{MPa}$ (Table 1). Finally, harmonic steel and stainless steel were assumed to have a linear elastic behaviour, as summarized in Table 1.

\section{Preliminary Analyses for the Façade Not Equipped by Devices}

5.1. Effects of the Positive and Negative Phases of Blast Load. Incremental dynamic analyses were developed in ABAQUS/ Explicit to investigate the behavioural trends of the façademodule not equipped by dissipative devices (cables rigidly connected). In this simulation phase, various blast load distributions (Level D-GSA) were taken into account to analyze the effects of the negative phase of the pressure-time history proposed in Figure 2.

Specifically, two load cases were considered:

(i) BL1: level D-GSA blast load, only positive phase;

(ii) BL2: level D-GSA blast load and positive and negative phases.

As suggested by Wei and Dharani [16], especially for blast loads having a not extremely violent positive phase, the negative phase could cause higher tensile stresses in the main components of the façade-module. Nevertheless, as discussed in the following section, this assumption does not apply to the studied cable-supported façade, and in general to strongly deformable systems.

The incremental analyses partly discussed in this paper had a total duration of $1.1 \mathrm{~s}$. In the initial step $(0<t<0.1 \mathrm{~s})$, the initial pretension force was applied to the cables as an imposed vertical displacement. In the second step $(0.1 \mathrm{~s}<$ $t<1.1 \mathrm{~s}$ ) also the air blast load was introduced in the FEmodel, in the form of a uniformly distributed, impulsive 


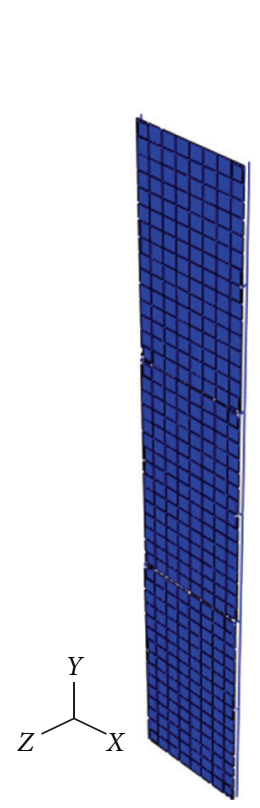

(a) $t=0.10 \mathrm{~s}$

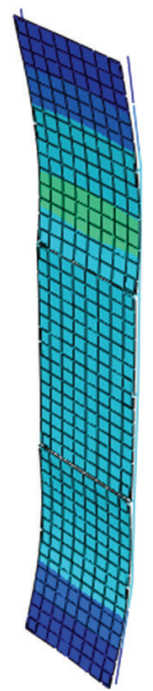

(b) $t=0.12 \mathrm{~s}$

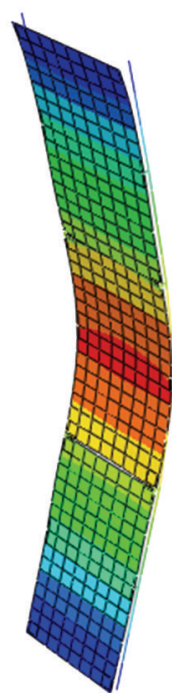

(c) $t=0.16 \mathrm{~s}$

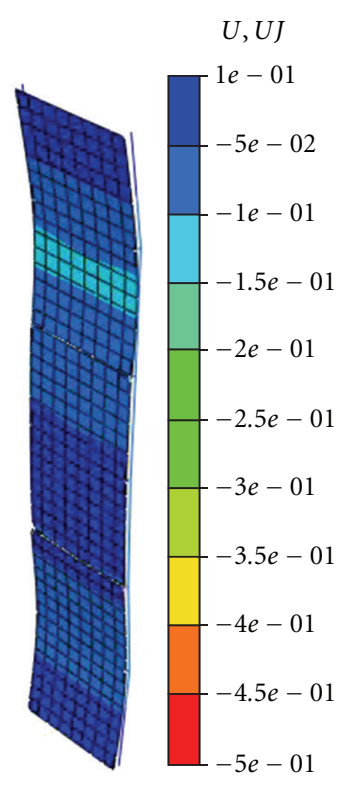

(d) $t=0.20 \mathrm{~s}$

FIGURE 4: Typical deformed configurations of the façade-module due to a high-level explosion (Level D-GSA, BL1). M01 FE-model.

pressure $q_{z \text {,blast }}$ acting orthogonally to the laminated glass panels and representative of the positive phase (BL1) or both the positive and negative phases (BL2) of a Level-D GSA explosion (Figure 2). Gravity loads were ignored, since they are associated to a negligible increase of stresses in glass panels and cables.

The typical dynamic response of the studied façademodule is proposed in Figure 4. Figures 4(a)-4(d) refer to specific instants $(t=0.10 \mathrm{~s}, 0.12 \mathrm{~s}, 0.16 \mathrm{~s}, 0.20 \mathrm{~s})$ and qualitatively emphasize the behavioural trends of the façade module immediately after the explosion has occurred.

In similar cable-supported curtain walls, the blast wave acts as a moving pressure. In the studied example, as observed by performing numerical simulations, the shock wave firstly interests the most rigid zones of the façademodule (the ends) and subsequently moves toward its center.

In addition, the occurring tensile stresses in its main structural components (laminated glass panels and cables) are generally proportional to the rigidity of the restraints. Consequently, the use of a system of bracing cables able to absorb part of the incoming energy due to explosion can be more advantageous than the use of rigid frame. In this context, it should also be noticed that the particular way the cables deform allows preventing the reaching in the glass panels of dangerous peaks of tensile stress in correspondence of the connectors. Nevertheless, large deflections should be expected and it cannot be ignored that this typology of blast resisting glazing façades still constitutes a rather sophisticated technological solution.

Undoubtedly, the glass panels constitute a critical component in the suspended curtain wall, since they present a brittle behaviour and are subjected to significant tensile stresses due to the design shock wave. Performed simulations allowed to notice that the maximum stresses occur at the corners of the middle glass panel (positions P2 and P4, Figures 6 and $\left.8, \sigma_{\text {glass, } \max }^{\mathrm{M} 01}=120 \mathrm{MPa}=\sigma_{R}\right)$. Significant peaks of stress, although lower than the used tensile strength for glass $\left(\sigma_{R}=120 \mathrm{MPa}\right)$, occur also at the centre of the panel (position P1, Figure 5) and near the lateral point-supports (position P3, Figure 7). However, as displayed in Figures $5-8$, no obvious differences can be noticed by comparing the maximum stresses in glass due to BL1 or BL2 loads. In both the circumstances, glass cracking interests only a restricted area of the panel and cracks open at $t=0.16 \mathrm{~s}$. The performed analyses allowed also to notice that the maximum tensile stresses approximately have equal magnitude at each instant in time in the two glass sheets constituting the examined laminated glass unit. As a result, as usually happens in layered shell models subjected to air blast waves, the second glass pane (in the studied example is the outer glass sheet, directly exposed to air blast loading) fails immediately after the first one $[5,15]$.

In Figure 9, also the maximum deflections of the façademodule due to BL1 or BL2 loads are compared. As shown, the design air blast load involves large displacements in the studied system, respectively, equal to $1 / 19\left(u_{\mathrm{cable}, \max }^{\mathrm{BL} 1}=\right.$ $0.45 \mathrm{~m}$, Figure 9$)$ or $1 / 18$ of the structural span $\left(u_{\text {cable, } \operatorname{BLax}}^{\mathrm{BL}}=\right.$ $0.48 \mathrm{~m}$, Figure 9). However, since explosions represent an exceptional loading condition for buildings, a prefixed level of damage should be expected. Preliminary calculations demonstrated that the maximum deflection of the studied glazing system subjected to ordinary wind loads $\left(q_{\text {wind }}=\right.$ $\left.0.75 \mathrm{kN} / \mathrm{m}^{2}\right)$ is $0.037 \mathrm{~m}(\approx 1 / 250$ of the structural span, [7, 8]).

Finally, Figure 10 proposes the maximum axial forces occurring in the cables due to BL1 or BL2 loads. Clearly, 


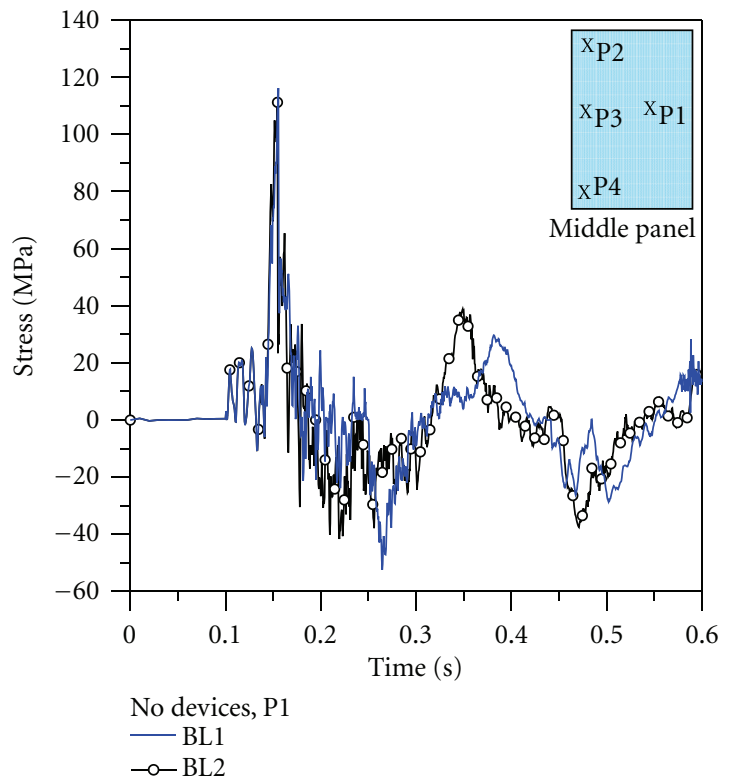

FIgURe 5: Comparison of maximum tensile stresses at location P1, as a function of time (ABAQUS). No devices. M01 FE-model, BL1 and BL2.

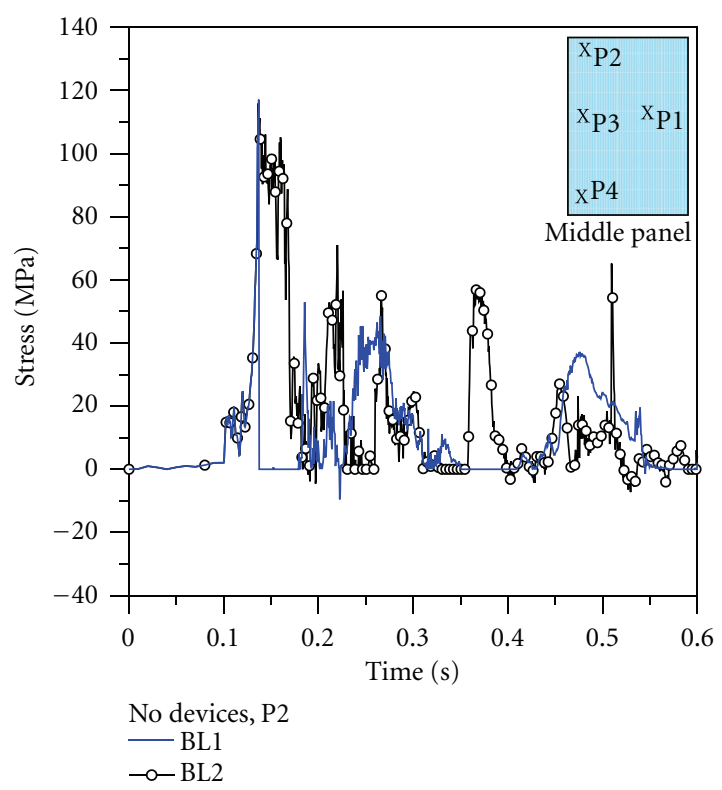

FIGURE 6: Comparison of maximum tensile stresses at location P2, as a function of time (ABAQUS). No devices. M01 FE-model, BL1 and BL2.

the positive impulse of explosion (BL1) involves elevated axial forces in the cables $\left(H_{\text {cable, } \max }^{\mathrm{BL} 1}=863 \mathrm{kN} \approx 2.87 \mathrm{H}_{0}\right.$, Figure $10, t=0.16 \mathrm{~s}$ ), but the initial pretension in the bearing system is preserved also after the explosion has been occurred $\left(H_{\text {cable,min }}^{\mathrm{BL1}}=205 \mathrm{kN} \approx 0.68 H_{0}\right.$, Figure $\left.10, t=0.22 \mathrm{~s}\right)$. On the contrary, the total impulse of explosion is associated to lower maximum forces in the cables $\left(H_{\text {cable, } \max }^{\text {BL2 }}=702 \mathrm{kN} \approx\right.$ $2.34 H_{0}$, Figure 10, $t=0.23 \mathrm{~s}$ ), but also to a significant loss of

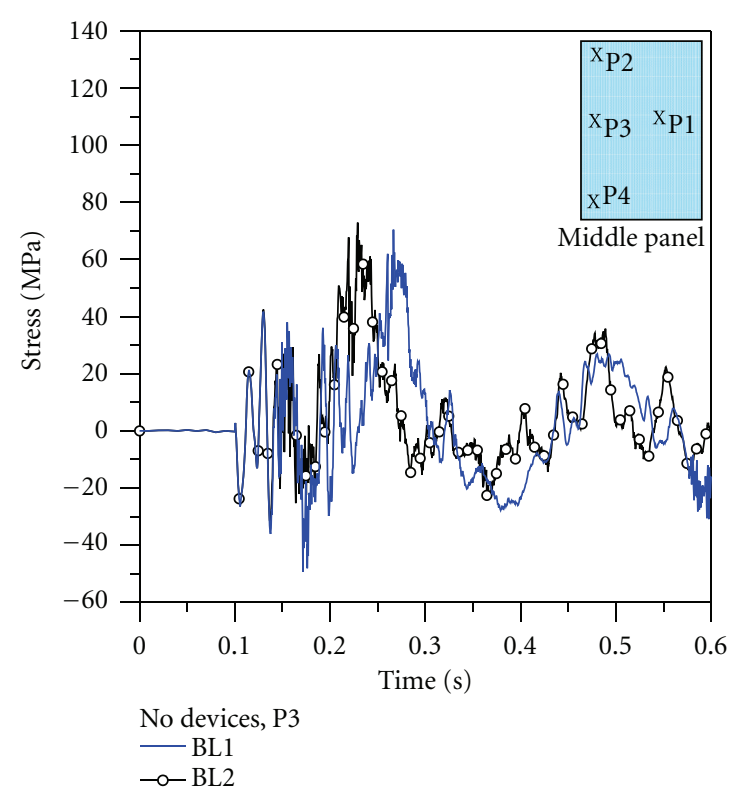

Figure 7: Comparison of maximum tensile stresses at location P3, as a function of time (ABAQUS). No devices. M01 FE-model, BL1 and BL2.

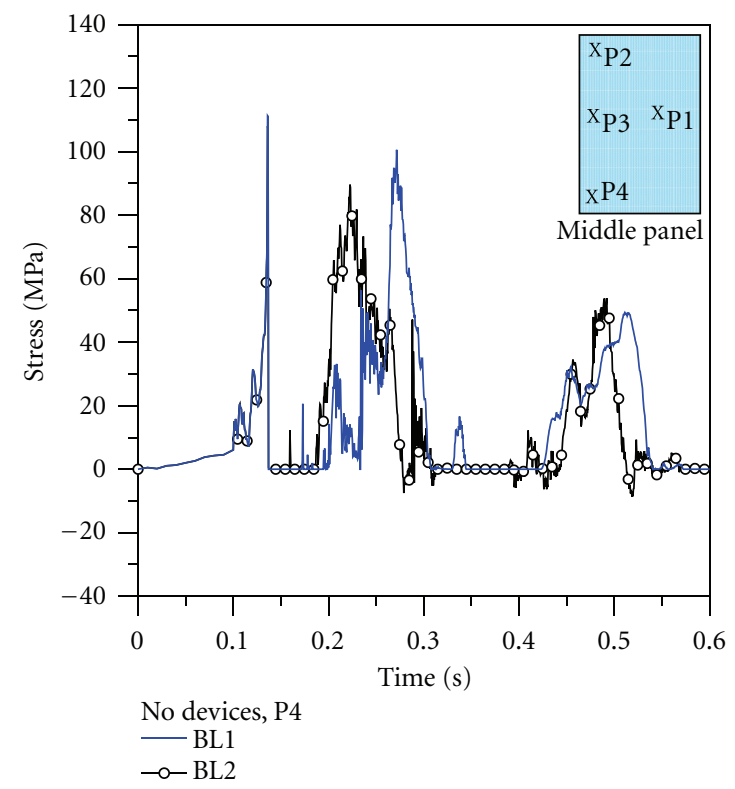

FIGURE 8: Comparison of maximum tensile stresses at location P4, as a function of time (ABAQUS). No devices. M01 FE-model, BL1 and BL2.

initial pretension $\left(H_{\text {cable,min }}^{\text {BL2 }}=134 \mathrm{kN} \approx 0.44 H_{0}\right.$, Figure 10 , $t=0.57 \mathrm{~s}$ ).

In general, since the ultimate characteristic strength for the used cables is $H_{\text {cable, Rk }}=1150 \mathrm{kN}$, the abrupt occurring of elevated axial forces in them should be avoided [7, 8]. Harmonic steel cables have in fact typical brittle-elastic behaviour and their rupture would cause the collapse of the entire suspended façade. Rationally, maximum axial forces 


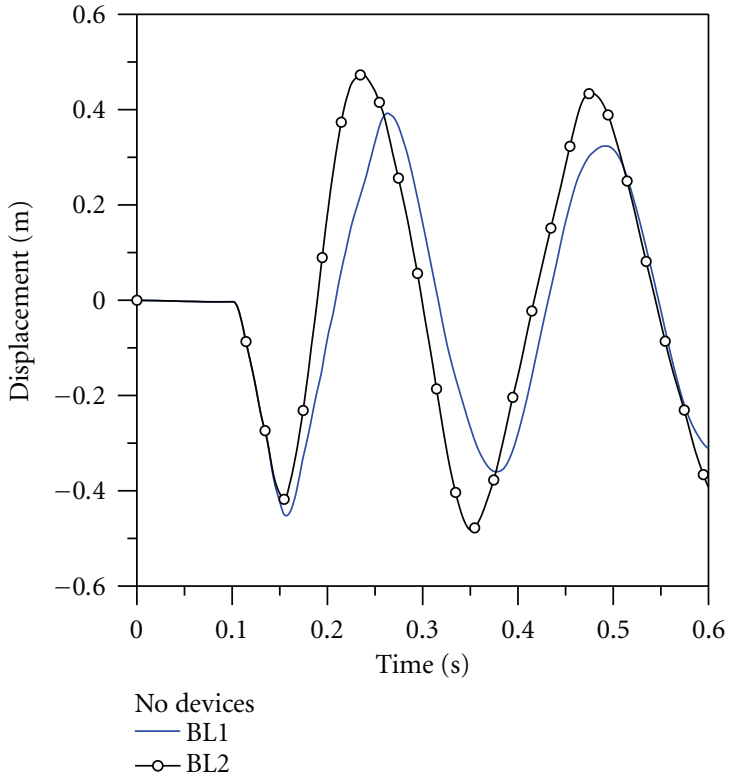

FIGURE 9: Comparison of mid-span cable deflection, as a function of time (ABAQUS). No devices. M01 FE-models, BL1 and BL2.

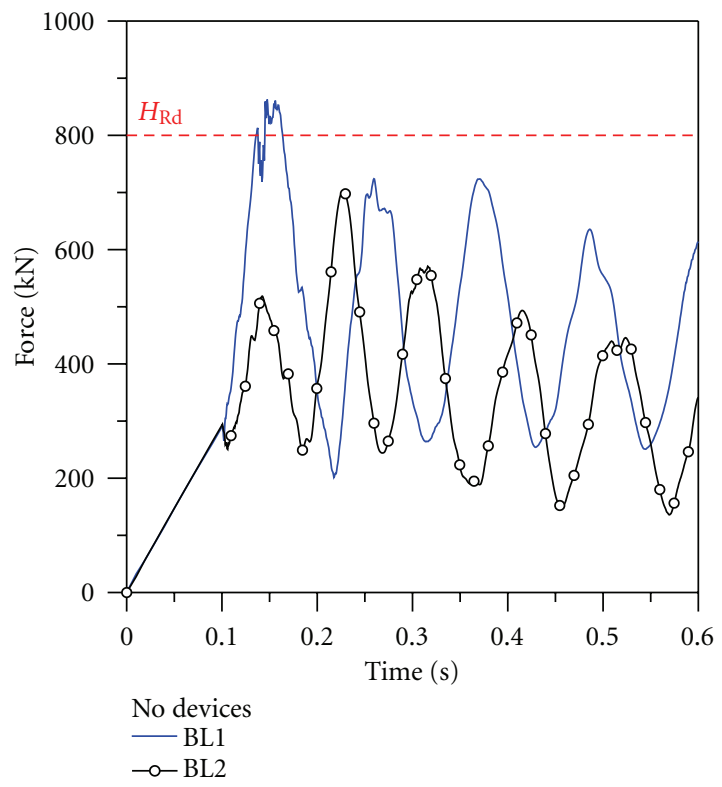

FIgURE 10: Comparison of axial force in the cables, as a function of time (ABAQUS). No devices. M01 FE-model, BL1 and BL2.

should be limited to $H_{\text {cable,Rd }} \approx 0.7 H_{\text {cable,Rk }}=800 \mathrm{kN}$. As shown in Figure 10, for the studied example, the BL2 load causes axial forces in cables that are clearly lower than the assumed design resistance $H_{\text {cable,Rd }}$. However, it should be noticed that the simulation of the behavioural trends of a similar cable-supported façade subjected to shock wave pressures involves a series of unavoidable simplifications that should be taken into account in the discussion of numerical results. The description of the shock wave as a pressure-time history (Figure 2), for example, does not allow taking into account the variability of the design blast load. Consequently, the analysis of the structural effects due to only the positive phase of the design blast load (BL1) could constitute a more prudential and conservative design condition.

In these hypotheses, with reference to Figure 10, if the cross-section is not adequate to resist to the design blast load, two possible solutions are offered to designers to avoid the collapse of the entire system. The first solution consists in increasing the cable diameter, and thus in overdimensioning the bracing system. The second solution, as proposed in the following sections, consists in introducing at the ends of the bearing cables a series of dissipative devices, able to mitigate the maximum effects of explosion and to provide additional dissipative capabilities to the façade [7].

5.2. Effects of Glass Cracking. Generally, cable-supported façades subjected to ordinary loads are designed to avoid the breaking of glass sheets and to preserve the integrity of the cladding wall. As a result, the glass panels are commonly assumed to behave linear-elastically. The possible cracking of glass sheets is tolerated, if limited to restricted surfaces, only when the glazing system is subjected to exceptional dynamic loads, as for example high-level blast waves. Because of this reason, in simulating the typical response of a cable-supported façade the possible glass cracking should be appropriately taken into account. In this paper, based on preliminary results previously discussed, additional incremental analyses were performed to highlight the effects of glass cracking on the dynamic response of the façade-module subjected to only the positive phase of the design blast load. Clearly, glass panes have a typical brittle behaviour and are the first component of the façade invested by the shock wave. Nevertheless, as proposed in Figures 5-8, cracks open only on a restricted area of glass panels.

For this purpose, a second FE-model has been developed for the studied façade-module (M02), obtained by assuming in M01 FE-model a linear elastic behaviour for glass. The main results are proposed in Figures 11-13.

If glass is assumed to behave linear elastically (M02 FEmodel), interesting modifications in distribution of stresses on the glass surface can be noticed. In particular, the maximum peak of stress occurs at location P1 and not at the corners (Figure $11, t=0.16, \sigma_{\text {glass, } \operatorname{Max}}^{\mathrm{M} 02}=138 \mathrm{MPa}$ ). At the same time, the maximum stresses monitored at locations $\mathrm{P} 2, \mathrm{P} 3$, and $\mathrm{P} 4$ have lower intensity $\left(\sigma_{\text {glass,max }}^{\mathrm{M} 02}=89 \mathrm{MPa}\right.$ at $\mathrm{P} 2, \sigma_{\text {glass, } \max }^{\mathrm{M} 02}=83 \mathrm{MPa}$ at P3, $\sigma_{\text {glass, } \max }^{\mathrm{M} 02}=87 \mathrm{MPa}$ at P4). Also in this circumstance, it is interesting to notice that since the peak of stress in P1 ( $\left.\sigma_{\text {glass, } \operatorname{Max}}^{\mathrm{M} 02}=138 \mathrm{MPa}\right)$ is only slightly higher than the used tensile strength for glass, in M01 FEmodel the glass cracking interests a restricted area of glass surface (the corners), and a negligible dissipation by damage of the incoming energy occurs in the glazing system. As a result, no obvious differences can be observed by comparing the maximum deflections of M01 and M02 FE-models (Figure 12). Similarly, the maximum axial forces occurring in the bearing cables due to the high-level explosion are practically identical (Figure 13). 


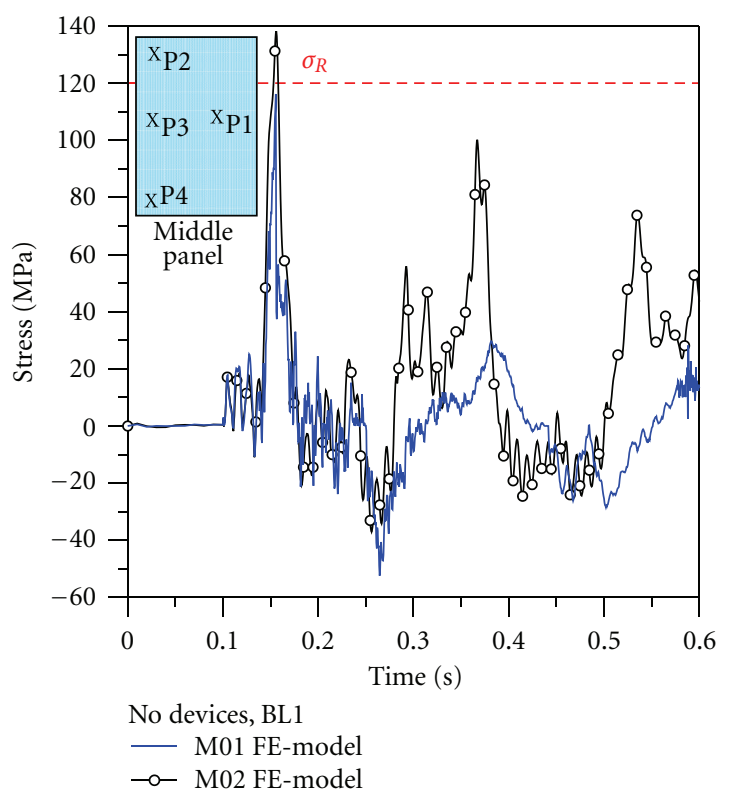

Figure 11: Comparison of maximum tensile stresses at location P1, as a function of time (ABAQUS). No devices. M01 and M02 FEmodels, BL1.

\section{FE Modeling of the Façade Equipped by Dissipative Devices}

In a subsequent numerical investigation phase, appropriate dissipative devices were introduced in M02 FE-model and applied at the ends of the bearing cables, to mitigate the effects of air blast loads on the studied façade-module.

The typical frictional dissipative device consists in a rigid-plastic mechanism, obtained by assembling three metallic plates and by connecting them with a slotted-bolted joint. Two outer plates and the bearing structure are joined together, whereas the middle plate is connected to the cable [7]. Similar devices commonly consist in stainless steel plates, although also brass plates have stable dynamic behaviour under cyclical loading conditions [17]. The parameter able to describe their dynamic behaviour is the sliding force $F_{s}$. If the external axial load is higher than $F_{s}$, the frictional device starts sliding, thus it reduces maximum axial forces in the cable and it partly dissipate in heat part of the input energy.

In this work, differing from investigations proposed in [7], various solutions were taken into account to find the optimal solution. Specifically, a series of dissipative devices was introduced at the top of each cable or at both their ends (Figure 14).

The structural and energy advantages provided by three possible solutions were examined:

(i) single vertical device: single longitudinal device applied at the top of each cable (Figure 14(a), V1);

(ii) double vertical devices: two longitudinal devices applied at the ends of each cable (Figure 14(b), V2);

(iii) double horizontal devices: two devices applied at the ends of each cable and working orthogonally to the

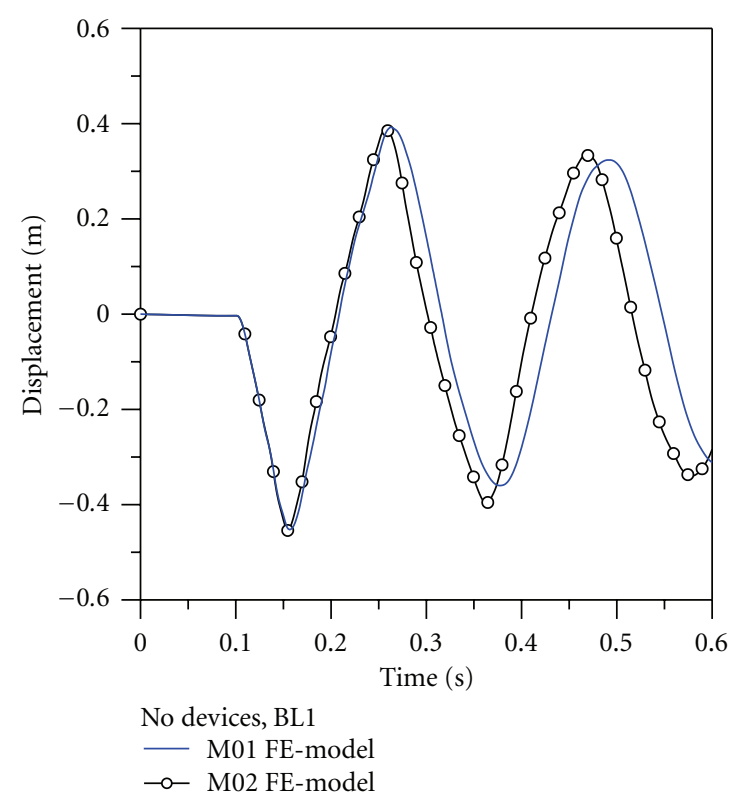

Figure 12: Comparison of midspan cable deflection, as a function of time (ABAQUS). No devices. M01 and M02 FE-models, BL1.

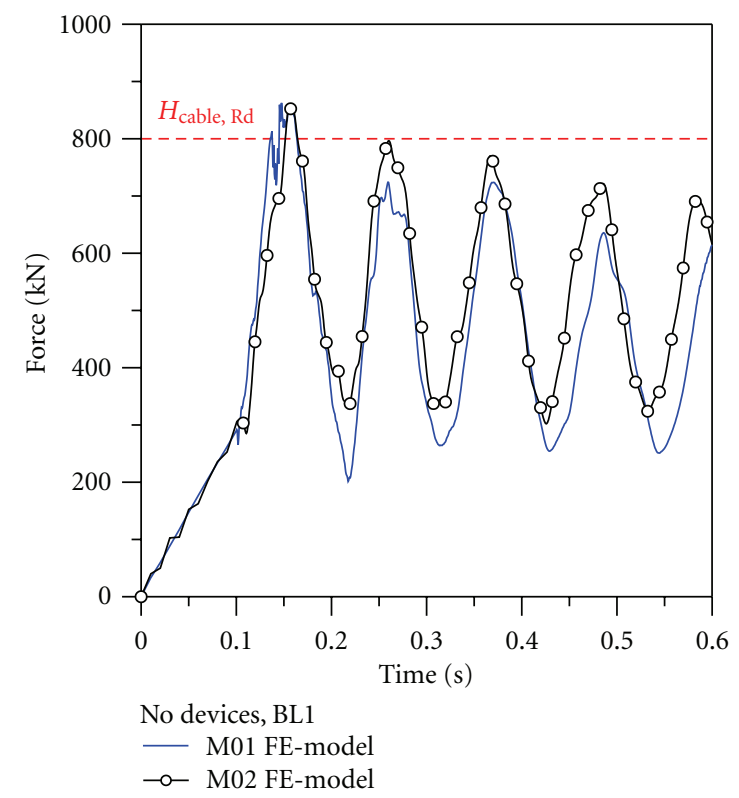

FIGURE 13: Comparison of axial force in the cables, as a function of time (ABAQUS). No devices. M01 and M02 FE-models, BL1.

plane of the curtain wall, in the direction of the acting blast pressure (Figure 14(c), H2).

Based on numerical results of preliminary simulations, the façade-module equipped by rigid-plastic dissipative devices was subjected only to the positive phase of a Level D air blast loading (BL1, Figure 2), since associated to higher tensile stresses in the structure components. Similarly, the possible cracking of glass panes was neglected.

Each dissipative device was introduced in M02 FE-model of the studied façade-module in the form of an axial spring, 
TABLE 2: Results of incremental analyses (ABAQUS). Glass stresses, deflections, and velocities. M02 FE-model, BL1.

\begin{tabular}{|c|c|c|c|c|c|c|}
\hline \multirow{2}{*}{ Devices } & \multicolumn{4}{|c|}{$\sigma_{\text {glass, } \max }[\mathrm{MPa}] ; \Delta \sigma[\%]$} & \multirow{2}{*}{$u_{\text {cable, } \max }[\mathrm{m}]$} & \multirow[b]{2}{*}{$v_{\text {cable, } \max }[\mathrm{m} / \mathrm{s}]$} \\
\hline & $\mathrm{P} 1$ & $\mathrm{P} 2$ & P3 & P4 & & \\
\hline - & 138.18 & 107.51 & 88.24 & 113.30 & 0.440 & 13.73 \\
\hline V1 & $125.63 ;-10$ & $114.30 ;+6$ & $86.52 ;-2$ & $121.54 ;+27$ & 0.442 & 14.08 \\
\hline $\mathrm{V} 2$ & $137.43 ;-1$ & $92.91 ;-16$ & $91.73 ;+4$ & $100.12 ;+12$ & 0.469 & 13.78 \\
\hline $\mathrm{H} 2$ & $133.89 ;-3$ & $88.28 ;-22$ & $95.23 ;+7$ & $105.39 ;+16$ & 0.481 & 14.03 \\
\hline
\end{tabular}

TABLE 3: Results of incremental analyses (ABAQUS). Cable axial forces, sliding of devices. M02 FE-model, BL1.

\begin{tabular}{lcccc}
\hline Devices & $H_{\text {cable, } \max }[\mathrm{kN}]$ & $H_{\text {cable, } \max } / H_{\text {cable, Rd }}[-]$ & $H_{\text {cable, } \min }[\mathrm{kN}]$ & $H_{\text {cable, } \min } / H_{0}[-]$ \\
\hline - & 859 & 1.074 & 302 & 1.007 \\
V1 & 798 & 0.998 & 171 & 0.570 \\
V2 & 769 & 0.962 & 0 & 0.000 \\
H2 & 751 & 0.939 & 281 & 0.936 \\
\hline
\end{tabular}

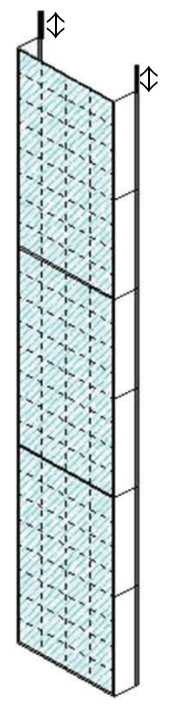

(a) Single vertical device, $\mathrm{V} 1$

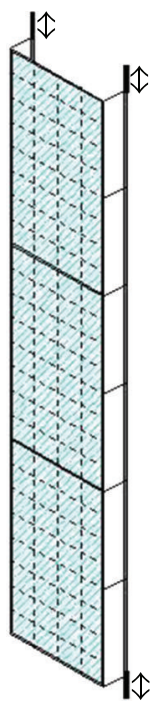

(b) Double horizontal devices, $\mathrm{H} 2$

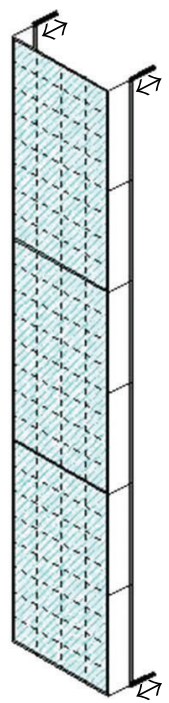

(c) Double vertical devices, V2
FIGURE 14: Working scheme of the façade-module equipped by frictional dissipative devices.

having a rigid-plastic characteristic curve. To ensure a cyclical rigid-plastic response of devices in presence of the design high-level explosion, an elastic stiffness $k_{D} \approx 1000 k_{\text {cable was }}$ assigned to each axial spring. At the same time, to avoid the reaching of elevated axial forces in the cables, the sliding force of each vertical device (Figures 14(a) and 14(b), V1 and V2) was preliminary assumed equal to $F_{s}=750 \mathrm{KN} \approx$ $2.5 \mathrm{H}_{0}$. Similarly, the value $F_{s}=80 \mathrm{KN} \approx 0.25 \mathrm{H}_{0}$ was used to characterize the behaviour of the horizontal devices (Figure 14(c), H2).

To simplify numerical simulations and to provide preliminary parametric results, the static friction coefficient of the proposed rigid-plastic devices was assumed equal to the dynamic friction coefficient. Undoubtedly, further experimental campaigns should be performed, to define

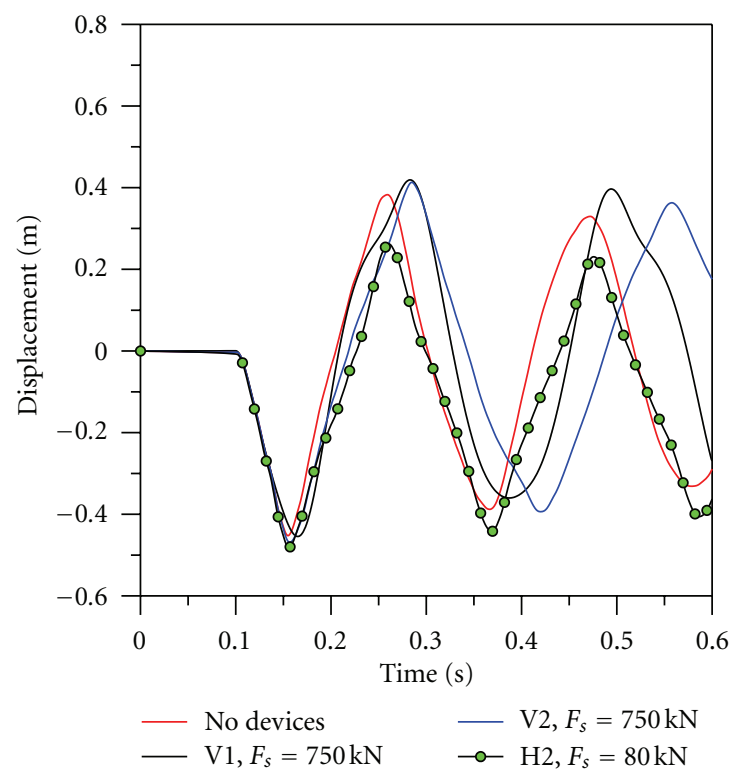

FIGURE 15: Comparison of mid-span cable deflection, as a function of time (ABAQUS). M02 FE-model, BL1.

accurately the main parameters characterizing the behaviour of similar slotted-bolted devices subjected to high-intensity impulsive loads and to reduce uncertainties in their modeling. However, numerical results proposed in the following sections could constitute an interesting starting point for additional investigations.

6.1. Parametric Dynamic Nonlinear Analyses. The obtained results were compared with the dynamic response of the façade-module not equipped by devices. The main comparisons are proposed in Figures 15 and 16 and summarized in Tables 2 and 3.

Concerning the maximum tensile stresses occurring in the middle glass panel, no significant modification can be noticed after the introduction of dissipative devices. As it 


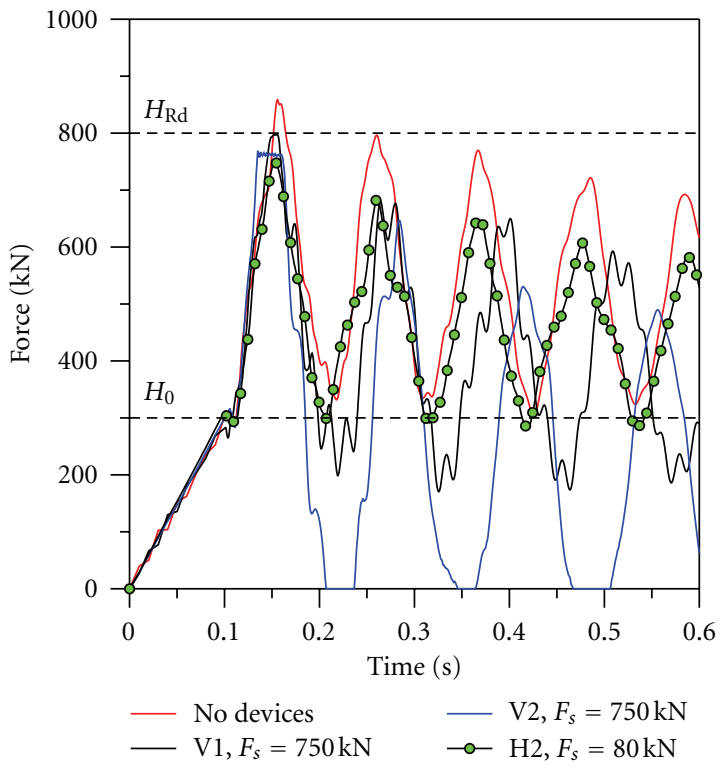

FIgURE 16: Comparison of axial force in the cables, as a function of time (ABAQUS). M02 FE-model, BL1.

would be expected, in fact, the sliding of devices allows mitigating especially the bearing cables [7]. This aspect should be taken into account in the design of the façademodule components, since the maximum tensile stresses in glass panels directly depend on the deflection of the glazing system.

In Table 2, the maximum tensile stresses occurring in the middle panel (P1, P2, P3, P4) are summarized for the investigated solutions (no devices, V1, V2, H2). To better highlight the effectiveness of each typology of device, also the differences between the results of the façade-module equipped or not by dissipative devices are proposed (in terms of the percentage $\Delta \sigma$ ). Additional results in Table 2 refer to maximum displacements and velocities reached by the moving façade-module, whereas in Table 3 numerical results are compared in terms of maximum/minimum axial forces in the cables and maximum sliding of each device.

By firstly comparing the maximum stresses occurring in the glass sheets, the single vertical device (V1) seems to constitute the more advantageous solution. In this specific circumstance, maximum stresses still occur at the center of the middle glass panel (position P1, Table 2) but they are appreciably reduced $(\Delta \sigma \approx-10 \%)$. Consequently, the variation of stresses near the point-spider connectors $(\Delta \sigma \approx$ $+6 \%$ in $\mathrm{P} 2, \Delta \sigma \approx-2 \%$ in $\mathrm{P} 3, \Delta \sigma \approx+27 \%$ in $\mathrm{P} 4)$ does not trouble the integrity of glass sheets. In contrary, double vertical devices (V2) are associated to noticeable reductions of stresses near the spiders $(\Delta \sigma \approx-16 \%$ in $\mathrm{P} 2, \Delta \sigma \approx$ $+4 \%$ in $\mathrm{P} 3, \Delta \sigma \approx+12 \%$ in $\mathrm{P} 4)$, but they are not able to reduce the maximum stress occurring in the panel at location $\mathrm{P} 1(\Delta \sigma \approx-1 \%)$, thus their mitigation effects on glass are negligible. Finally, as shown in Table 2, double horizontal devices $(\mathrm{H} 2)$ provide structural benefits in the glass sheets that are comparable to those of double vertical devices. Specifically, $\mathrm{H} 2$ devices are associated to noticeable modifications of stresses near the spider-connectors $(\Delta \sigma \approx$ $-22 \%$ in $\mathrm{P} 2, \Delta \sigma \approx+7 \%$ in $\mathrm{P} 3, \Delta \sigma \approx+16 \%$ in $\mathrm{P} 4$ ), but the maximum stress at location $\mathrm{P} 1$ is approximately equal to that occurring in the façade-module not equipped by dissipative devices $(\Delta \sigma \approx-3 \%)$.

Undoubtedly, the presence of a sliding mechanism at the ends of the bearing cables involves a drop in their axial force $H_{0}$, and consequently an increase of the maximum deflection in the façade-module. As a result, multiple factors should be taken into account in the choice of the optimal technological solution.

As proposed in Figure 15 and Tables 2 and 3, the use of a single vertical device slightly modifies the maximum deflection of the façade $\left(u_{\text {cable, } \operatorname{Vax}}^{\mathrm{V} 1}=0.442 \mathrm{~m}\right)$, because the sliding of the device itself is negligible $\left(s_{\max }^{\mathrm{Vl}}=0.009 \mathrm{~m}\right)$. At the same time, $\mathrm{V} 1$ devices allow to cut down significantly the maximum axial forces in the cables $\left(H_{\text {cable, } \operatorname{Vax}}^{\mathrm{Vl}}=0.798 \mathrm{KN}=\right.$ $\left.0.998 H_{\text {cable,Rd }}\right)$ and to preserve, due to their negligible sliding, an appropriate minimum pretension force in them $\left(H_{\text {cable, } \operatorname{lin}}^{\mathrm{Vl}}=0.171 \mathrm{KN}=0.57 H_{0}\right)$.

In contrast, $\mathrm{V} 2$ devices undergo large slidings $\left(s_{\max }^{\mathrm{V} 2}=\right.$ $0.023 \mathrm{~m})$, thus they are able to provide an interesting reduction of maximum axial forces in the cables $\left(H_{\text {cable, } \max }^{\mathrm{V} 2}=\right.$ $\left.0.769 \mathrm{KN}=0.996 H_{\text {cable,Rd }}\right)$, but not to preserve a minimum pretension force in them $\left(H_{\text {cablemin }}^{\mathrm{V} 2}=0\right)$. To guarantee the stability of the suspended curtain wall, the complete detensioning of cables should be avoided and at least a minimum pretension force $H_{\text {cablemin }} \geq 0.5 H_{0}$ should be preserved.

Finally, numerical simulations allowed to notice that $\mathrm{H} 2$ devices, although associated to extreme slidings $\left(s_{\max }^{\mathrm{H} 2}=\right.$ $0.082 \mathrm{~m}$ ), are able to appropriately mitigate the bearing cables $\left(H_{\text {cable,max }}^{\mathrm{H} 2}=751 \mathrm{kN}=0.939 H_{\text {cable,Rd }}\right)$ and to preserve an opportune pretension in them after the explosion has been occurred $\left(H_{\text {cable, min }}^{\mathrm{H} 2}=281 \mathrm{kN}=0.936 H_{0}\right)$. Nevertheless, their working mechanism (orthogonally to the plane of the façade) and their large sliding could seriously trouble the aesthetic concept and the architectural planning of the curtain wall. At the same time, the structural advantages they provide in cables, if compared to those provided by the use of V1 devices, do not justify the doubling of costs.

6.2. Dimensioning of the Dissipative Device. The structural efficacy of a single vertical dissipative device having a rigidplastic characteristic behaviour is directly proportional to the amount of its sliding force $F_{s}$. An appropriate estimation of $F_{s}$ is in fact fundamental to limit the maximum axial forces in the bearing cables, as well as to preserve an adequate pretension force in them and to avoid extreme deformed configurations in the façade-module.

Further parametric incremental analyses were performed on the FE-model of the façade-module equipped by single vertical devices (V1), by varying $F_{s}$ in a preestablished range $\left(1.0 H_{0} \leq F_{s} \leq 3.0 H_{0}\right.$, with $\left.k_{D}=1000 k_{\text {cable }}\right)$, to investigate its effects on the dynamic response of the curtain wall. The obtained results were analyzed and compared especially in terms of maximum/minimum axial forces in cables (Figure 17). Additional results are proposed in Table 4. 
TABLE 4: Results of incremental analyses (ABAQUS, M02 FE-model, BL1). Façade with single vertical devices (V1). Cable axial forces, sliding of devices.

\begin{tabular}{|c|c|c|c|c|c|c|c|}
\hline Devices & $F_{s} / H_{0}[-]$ & $H_{\text {cable, } \max }[\mathrm{kN}]$ & $H_{\text {cable, } \max } / H_{\text {cable, Rd }}[-]$ & $H_{\text {cable, } \min }[\mathrm{kN}]$ & $H_{\text {cable, } \min } / H_{0}[-]$ & $s_{\max }[\mathrm{m}]$ & $u_{\text {cable, } \max }[\mathrm{m}]$ \\
\hline $\mathrm{V} 1, F_{s}=750 \mathrm{kN}$ & 2.5 & 798 & 0.998 & 171 & 0.570 & 0.009 & 0.442 \\
\hline $\mathrm{V} 1, F_{s}=600 \mathrm{kN}$ & 2.0 & 626 & 0.783 & 25 & 0.083 & 0.026 & 0.472 \\
\hline $\mathrm{V} 1, F_{s}=480 \mathrm{kN}$ & 1.6 & 522 & 0.653 & 0 & 0.000 & 0.044 & 0.500 \\
\hline $\mathrm{V} 1, F_{s}=360 \mathrm{kN}$ & 1.2 & 387 & 0.484 & 0 & 0.000 & 0.064 & 0.570 \\
\hline
\end{tabular}

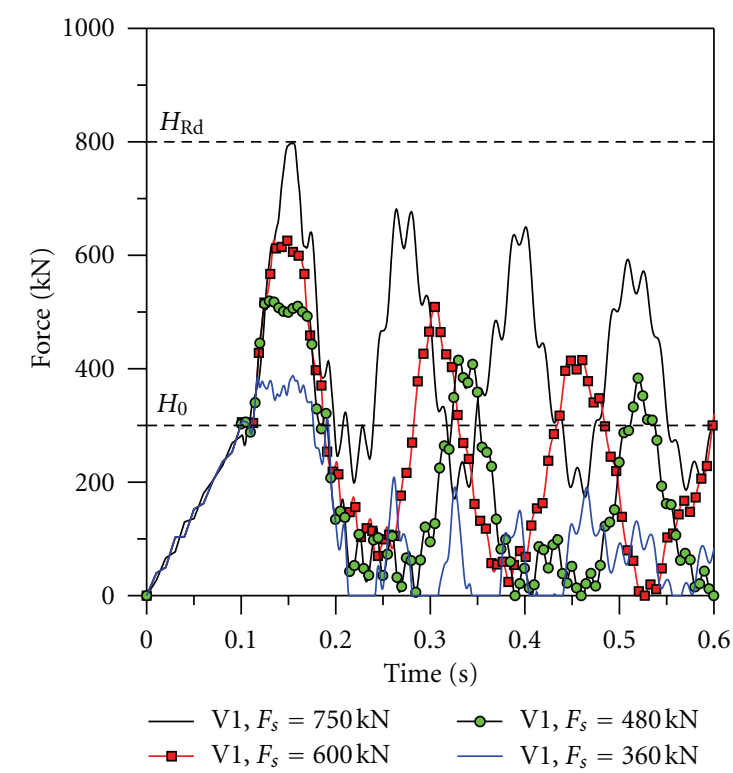

FIGURE 17: Comparison of axial force in the cables, as a function of time (ABAQUS). Single vertical device. M02 FE-model, BL1.

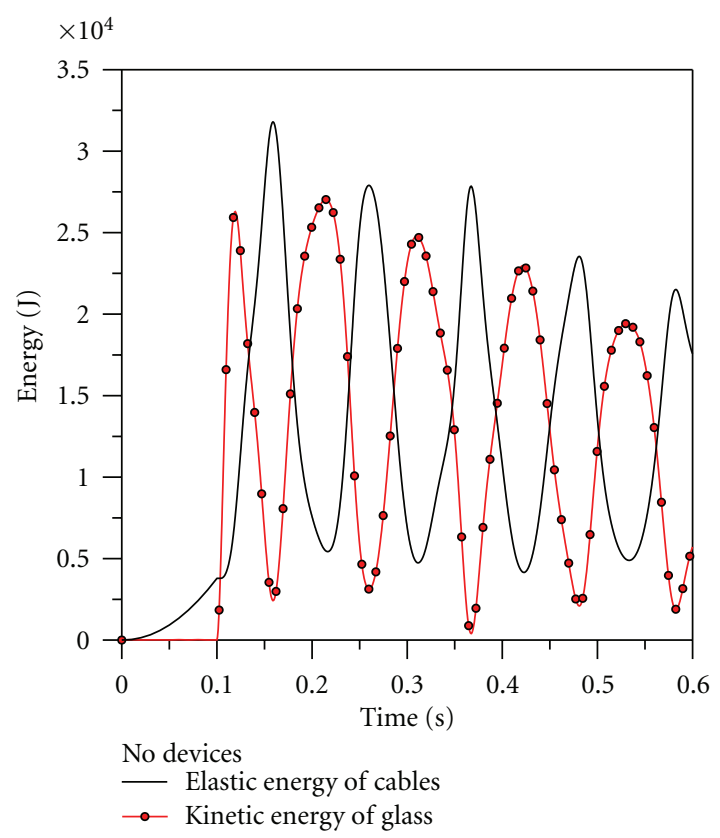

Figure 18: Energy terms of the façade-module (ABAQUS). No devices. M02 FE-model, BL1.
As shown in Figure 17, the sliding of V1 devices involves a marked reduction of maximum axial forces in cables. On the other hand, the sliding itself causes a non-negligible loss of the initial pretension force. Parametric analyses showed that to optimize the efficacy of the proposed dissipative mechanism, the sliding force $F_{s}$ should be equal to $F_{s} \cong$ $2.0 H_{0}-2.5 H_{0}$ [7].

In this context, additional energy considerations for the façade-module equipped or not by dissipative devices could be useful to understand the behavioural trends of the studied glazing system subjected to a high-level air blast load.

In Figures 18 and 19, the energy terms involved in the dynamic response of the studied façade-module rigidly connected (no dissipative devices) or equipped by single vertical devices (V1, $F_{s}=750 \mathrm{kN}=2.5 \mathrm{H}_{0}$ ) are proposed. As known, an explosion is typically associated to an abrupt and significant increase of energy $E_{\text {blast }}$. This energy is absorbed in a very short period by the main components of the façade-module (the glass panels, the bearing cables and the proposed dissipative devices, if present). Moreover, since damping has no effect in presence of similar impulsive loads, no significant energy dissipation occurs.

In this context, let us examine the curves proposed in Figure 18 and referred to the façade-module not equipped by devices. In Figure 18, the total increment of energy $\Delta E_{0}=E_{\text {blast }}$ stored by the façade-module in the instant in which it reaches the maximum deformed configuration $(t=0.16 \mathrm{~s})$ can be assumed equal to the increment $\Delta E_{\text {cable }}$ of elastic energy in cables. In fact, the increment of kinetic energy $\Delta E_{\text {glass }}$ in glass panels at the instant $t=0.16 \mathrm{~s}$ is approximately null. As a result, the maximum increment of energy in the façade-module due to the design blast load can be rationally expressed as:

$$
\begin{aligned}
\Delta E_{0} \approx \Delta E_{\text {cable }} & =\frac{1}{2} k_{\text {cable }}\left(z_{\text {final }}^{2}-z_{\text {initial }}^{2}\right) \\
& =\frac{1}{2} \frac{H_{\text {blast }}^{2}+2 H_{0} H_{\text {blast }}}{k_{\text {cable }}},
\end{aligned}
$$

where $H_{\text {blast }}$ is the maximum increment of axial forces in the cables due to explosion $\left(H_{\text {blast }}=859 \mathrm{kN}\right.$ in the studied example $[7,8]), z_{\text {final }}=\left(H_{0}+H_{\text {blast }}\right) / k_{\text {cable }}$ is the maximum elongation of the cables due to $H_{\text {blast }}$, and $z_{\text {initial }}=H_{0} / k_{\text {cable }}$.

Contrarily, if vertical devices are used (e.g., $\mathrm{V} 1$, with $F_{s}=$ $750 \mathrm{kN}$ ), the maximum axial stress in the cables due to the design air blast load should be at least equal to $F_{s}<H_{\text {blast }}$. As a result, the maximum increase of elastic energy in cables is

$$
\Delta E_{\text {cable }}^{\text {device }}=\frac{1}{2} \frac{F_{s}^{2}-H_{0}^{2}}{k_{\text {cable }}}<\Delta E_{\text {cable }} \text {. }
$$


As shown in Figure 19, the maximum increase $\Delta E_{\text {cable }}^{\text {device }}(t=$ $0.16 \mathrm{~s}$ ) is in fact lower than $\Delta E_{\text {cable }}$ (Figure $18, t=0.16 \mathrm{~s}$ ). Clearly, an optimal value for $F_{s}$ should be assumed in the dimensioning of the friction mechanism, since an extremely rigid device $\left(F_{s}>2.8 H_{0}\right.$, in the studied example), should not be able to slide in presence of a high-level air blast load. As a result, the potentiality of the proposed devices could not be exploited at best. If opportunely calibrated, friction devices not only allow limiting the maximum axial forces in the cables, but due to their sliding $s$, they also allow dissipating in heat a part of the incoming energy due to explosion (Figure 19):

$$
\Delta E_{\text {friction }}=F_{s} s .
$$

In addition, as shown in Figure 19, the proposed devices do not provide obvious modifications in the kinetic energy stored by the glass panels. As it would be expected, the maximum increment $\Delta E_{\text {glass }}^{\text {device }}$ (Figure $19, t=0.16 \mathrm{~s}$ ) is approximately equal to $\Delta E_{\text {glass }}$ (Figure $18, t=0.16 \mathrm{~s}$ ). However, major benefits can be noticed in the following instants $(t>$ $0.20 \mathrm{~s})$.

Certainly, the variability of the design blast loading and the friction parameters characterizing the dynamic behaviour of the presented mechanism strongly affect the dynamic response of a similar cable-supported glazing system. Nevertheless, the discussed numerical results could constitute useful information for designers, and a starting point for advanced stages in the design of similar blast resistant cable-supported systems.

\section{Conclusions}

The dynamic behaviour of a cable-supported blast-resistant glazing façade subjected to high-level blast loads is investigated through numerical simulations. To describe realistically the dynamic response of the examined system, a detailed FE-model is presented (M01). The M01 FEmodel allows to investigate the dynamic behaviour of each structural component (laminated glass, 2-hole and 4-hole spider connectors, pretensioned cables). At the same time, it allows taking into account the possible cracking of glass panels due to explosion, by means of a brittle cracking model based on fracture mechanics. Nevertheless, as shown by performing incremental analyses with a linear elastic FE-model (M02), glass breakage is limited to a restricted area of glass sheets, thus it is negligible. On the contrary, the critical components in similar cable-supported façade subjected to high-level blast loads are the bearing cables: since they present typical brittle-elastic behaviour, the abrupt occurring of elevated axial forces due to explosion should be avoided to preserve the stability of the entire curtain wall. At the same time, also their maximum deflection should be opportunely limited, to preserve the integrity of pointsupported glass panels interacting with them.

To limit these effects, the advantages provided by single or double frictional devices, installed at the top (or at both the ends, vertically or horizontally) of the pretensioned cables, were analyzed. As proposed in the paper, the single

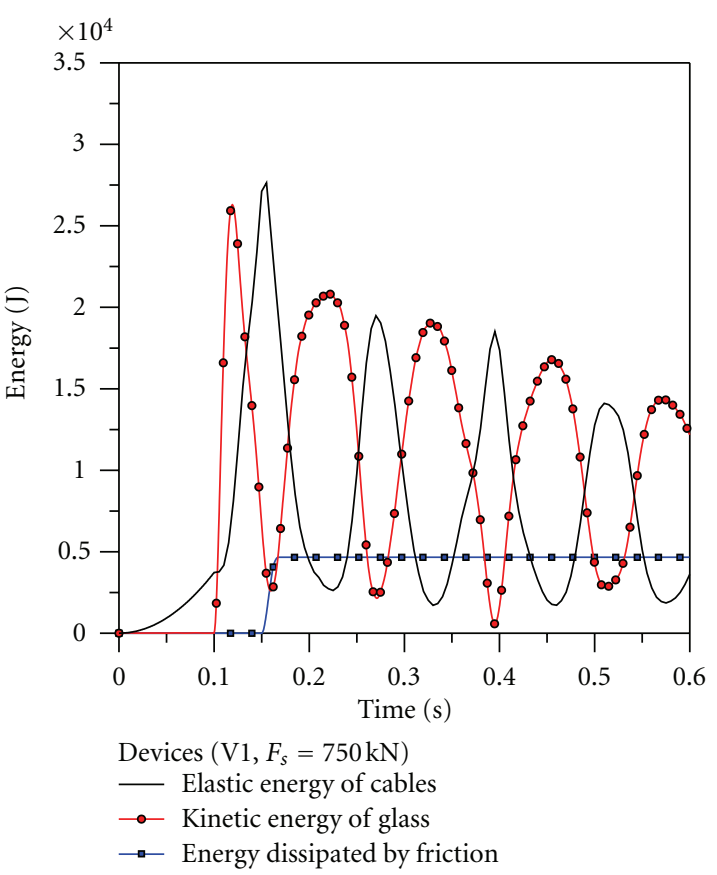

FIGURE 19: Energy terms of the façade-module (ABAQUS). Single vertical device $\left(\mathrm{V} 1, F_{s}=750 \mathrm{kN}=2.5 \mathrm{H}_{0}\right)$. M02 FE-model, BL1.

vertical devices constitute the most beneficial technological solution. Specifically, their use involves interesting advantages in the global behaviour of the cable-supported façade, since they cut down the maximum axial forces in the cables when explosion occurs, without significantly increasing the corresponding deflections. At the same time, maximum tensile stresses in glass panes weakly reduce.

\section{References}

[1] S. L. Chan, Y. Liu, and A. Lee, "Nonlinear analysis of pretensioned glass wall facade by stability function with initial imperfection," Frontiers of Architecture and Civil Engineering in China, vol. 4, no. 3, pp. 376-382, 2010.

[2] Q. S. Li and G. Q. Li, "Time-dependent reliability analysis of glass cladding under wind action," Engineering Structures, vol. 27, no. 11, pp. 1599-1612, 2005.

[3] R. Q. Feng, L. L. Zhang, Y. Wu, and S. Z. Shen, "Dynamic performance of cable net facades," Journal of Constructional Steel Research, vol. 65, no. 12, pp. 2217-2227, 2009.

[4] H. S. Norville and E. J. Conrath, "Simplified Design Procedure for Blast Resistant Glazing," Glass Processing Days, 2001.

[5] M. Larcher, G. Solomos, F. Casadei, and N. Gebbeken, "Experimental and numerical investigations of laminated glass subjected to blast loading," International Journal of Impact Engineering, vol. 39, no. 1, pp. 42-50, 2012.

[6] D. C. Weggel and B. J. Zapata, "Laminated glass curtain walls and laminated glass lites subjected to low-level blast loading," Journal of Structural Engineering, vol. 134, no. 3, pp. 466-477, 2008.

[7] C. Amadio and C. Bedon, "Elastoplastic dissipative devices for the mitigation of blast resisting cable-supported glazing façades," Engineering Structures, vol. 39, pp. 103-115, 2012. 
[8] C. Amadio and C. Bedon, "Viscoelastic spider connectors for the mitigation of cable-supported façades subjected to air blast loading," Engineering Structures, vol. 42, pp. 190-200, 2012.

[9] F. Wellershoff, "Design methods and structural components of blast enhanced façades," in Proceedings of the Challenging Glass 3-International Conference on Architectural and Structural Applications of Glass, F. Bos, C. Louter, R. Nijsse, and F. Veer, Eds., pp. 28-29, IOS Press, TU Delft, The Netherlands, June 2012.

[10] GSA-TSO1-2003, "Test Method for Glazing and Window Systems Subject to Dynamic Overpressure Loadings," U.S. General Service Administration.

[11] P. S. Bulson, Explosive Loading of Engineering Structures, E \& FN Spon, Chapman \& Hall, London, UK, 1997.

[12] TM 5-1300, The Design of Structures to Resist the Effects of Accidental Explosions, U.S. Department of the Army, The Navy and the Air Force, Technical Manual, Washington, DC, USA, 1990.

[13] ABAQUS ver. 6.5 User Manual, Hibbitt, Karlsson and Sorensen, Pawtucket, RI, USA, 2005.

[14] E. Sommer, "Formation of fracture "lances" in glass," Engineering Fracture Mechanics, vol. 1, no. 3, pp. 539-546, 1969.

[15] C. Amadio and C. Bedon, "Blast analysis of laminated glass curtain walls equipped by viscoelastic dissipative devices," Buildings, vol. 2, no. 3, pp. 359-383, 2012.

[16] J. Wei and L. R. Dharani, "Response of laminated architectural glazing subjected to blast loading," International Journal of Impact Engineering, vol. 32, no. 12, pp. 2032-2047, 2006.

[17] J. H. Park, B. W. Moon, K. W. Min, S. K. Lee, and C. Kyeong Kim, "Cyclic loading test of friction-type reinforcing members upgrading wind-resistant performance of transmission towers," Engineering Structures, vol. 29, no. 11, pp. 3185-3196, 2007. 

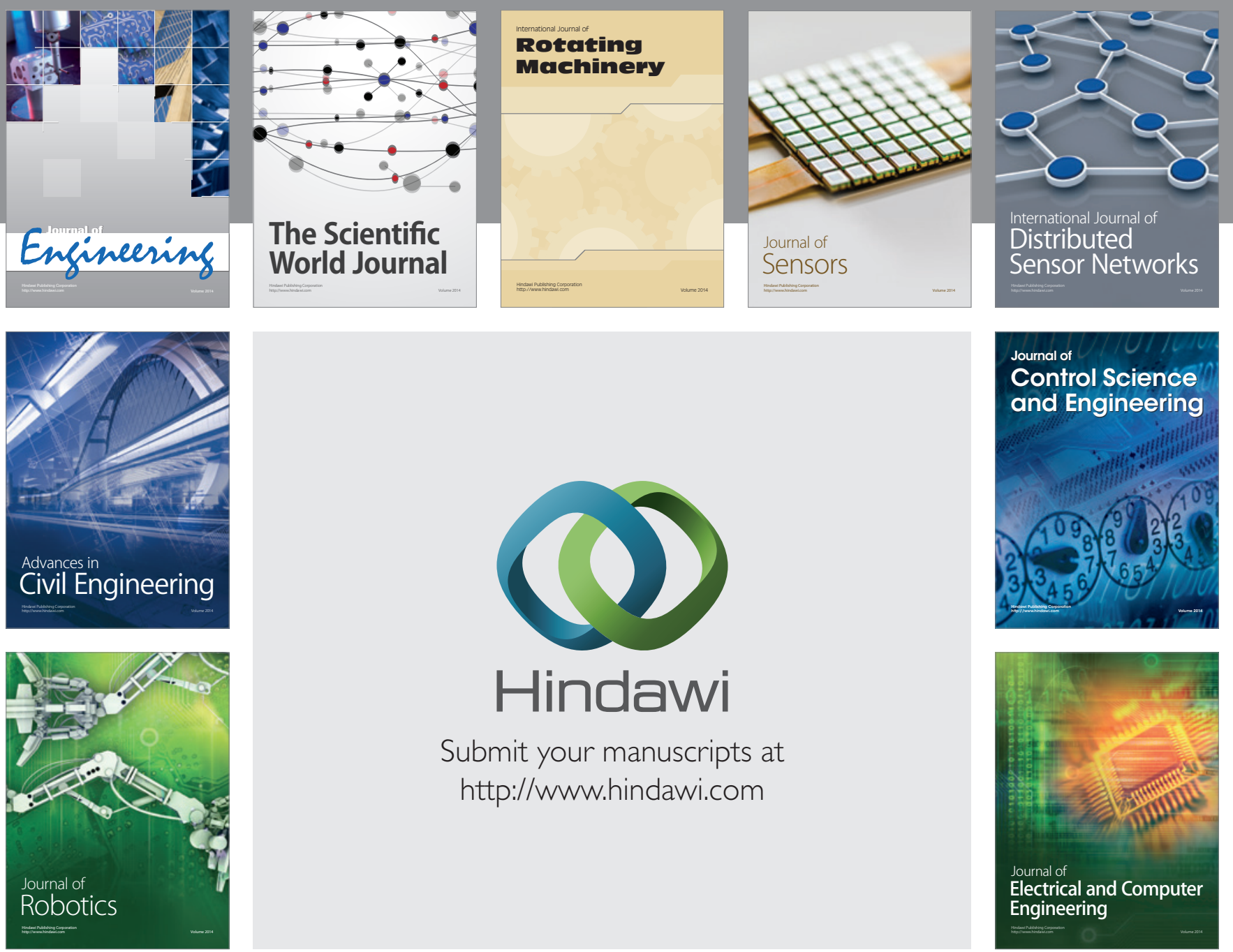

Submit your manuscripts at

http://www.hindawi.com
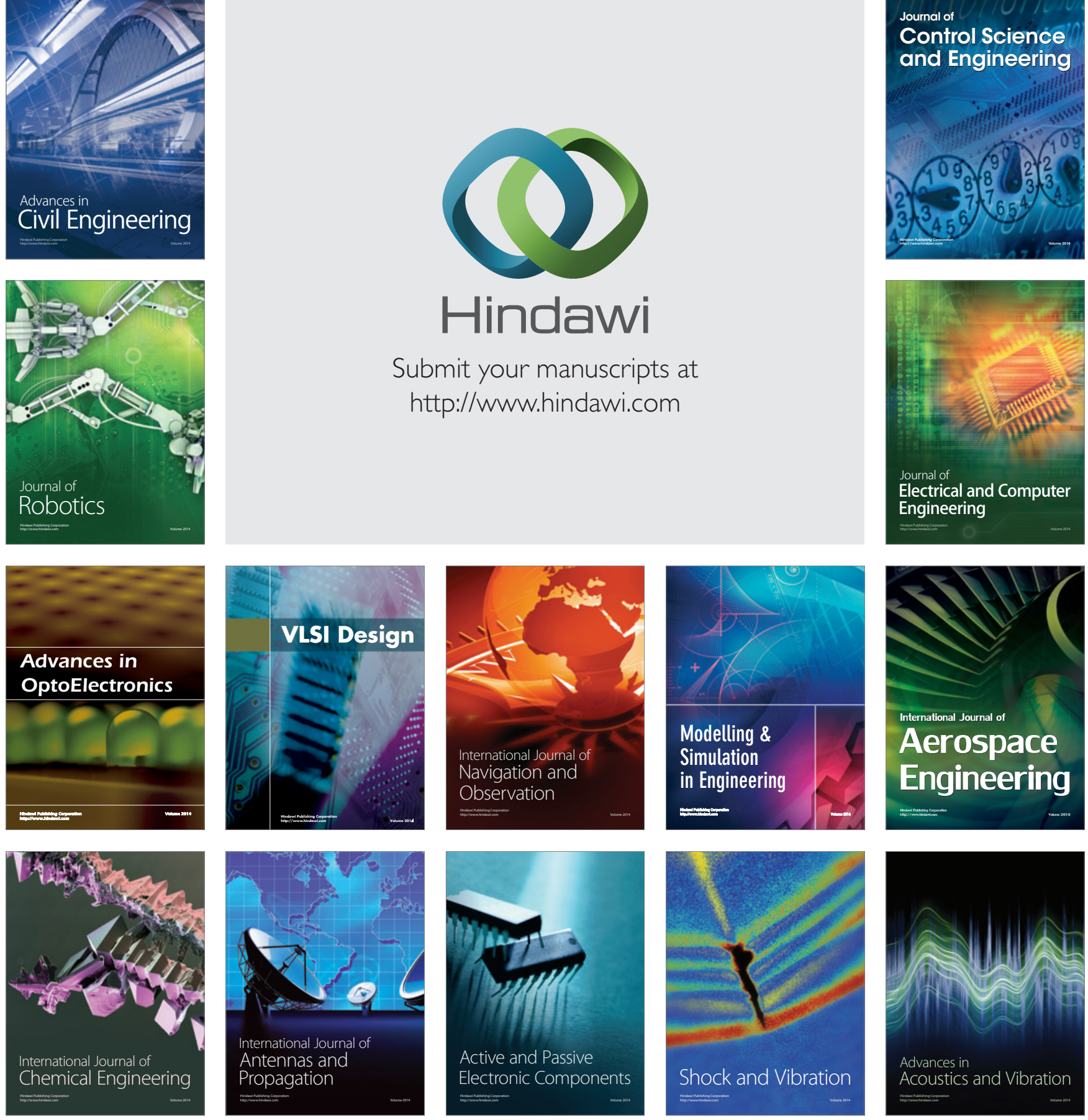